\title{
Mental Health, Alcohol Consumption, and Partnerships After the Third Wave During the Corona Pandemic - A Comparison of German Psychology Students and Other Students
}

\section{Max Supke ( $\square$ m.supke@tu-braunschweig.de)}

Technische Universität Braunschweig

Prof. Dr. Wolfgang Schulz

Technische Universität Braunschweig

\section{Research Article}

Keywords: university, alcohol consumption, psychology students, third wave, corona pandemic, mental health

Posted Date: September 28th, 2021

DOI: https://doi.org/10.21203/rs.3.rs-927326/v1

License: (9) This work is licensed under a Creative Commons Attribution 4.0 International License.

Read Full License 


\section{Abstract \\ Background.}

At the end of winter and in spring 2021, Germany experienced the third wave of the corona pandemic leading to a strict lockdown. This study compares psychology students and students of other subjects in terms of their mental health, alcohol consumption, and partnerships after the third wave during the corona pandemic.

\section{Methods.}

The study sample consists of $n=127$ (female: $n=108$, male: $n=19$ ) psychology students and $n=579$ (female: $n=322$, male: $n=257$ ) students of other subjects from the TU Braunschweig in Germany. These students participated in an online survey in June and July 2021. The comparison was performed separately for women and men. The PHQ-9 and GAD-7 were used to assess depressive mood problems and worrying.

\section{Results.}

Significantly fewer female psychology students were above the cut-off for clinically relevant mood problems (31.5\%), worrying (22.2\%), and both simultaneously (19.4\%) compared to other female students (mood: 66.1\%; worrying: $41.9 \%$; both: $39.8 \%$ ). The small sample of male psychology students showed similar tendencies; however, the results were not significant. While female psychology students rated their general health and life satisfaction significantly higher, male psychology students had significantly fewer concerns about their professional future compared to their respective counterparts. No significant effects were found for alcohol consumption and partnerships.

\section{Conclusion.}

We found hints that psychology students, especially female students, appear to be less psychologically distressed in terms of depressive mood problems and worrying during the corona pandemic. Better mental health knowledge could be a possible explanation for these findings.

\section{Background}

Life has been defined by the corona pandemic worldwide for one and a half years. Infection figures are constantly changing, and restriction measures have been tightened or loosened accordingly ever since. At the end of winter and in spring 2021, Germany experienced the third wave of the corona pandemic. Especially in March, April, and May 2021, a lot of new infections with the disease were reported and many restrictions were applied. Germany was in a strict lockdown for several months during this period. 
Previous research has shown that people report increased anxiety and depressive symptoms in response to a crisis such as a pandemic (e.g., [1], [2]). Many studies are focusing on the well-being of the older generation or other at-risk groups who are likely to be infected and suffer a severe course of the disease (e.g., [3]). Furthermore, how family's experience the pandemic is another field of research with great relevance (e.g., [4]). However, young adults, especially, university students have hardly been considered in public discussions and research for a long time in Germany so far.

The corona pandemic has changed the lives of students around the world [5]. Studies from other countries, such as for example Switzerland [6] or France [7], show that students experienced greater stress during the pandemic. Furthermore, hints were found that female students could be more affected by the pandemic than male students (e.g., [6-8]). Additionally, a German study from Busse et al. [9] found that female students reported an increase in the number of consumed drinks in May 2020.

Since each country took different measures to contain the virus, the comparability of studies from different countries is somewhat limited, which is why we focus mostly on studies from Germany to compare our findings.

In Germany, university students experienced drastic changes over a long period of time in their daily lives. Through corona, most of university life took place online. Many students spent the whole day in front of their computers, so every day was the same for them. Students reported that social and cultural activities, hobbies as well as dating activities were more restricted than before the pandemic [10], which made it difficult to use them as a balance to the daily university life.

Data from before the pandemic of German students show that in $201314.2 \%$ of the German students $(N=1,707 ; 73.1 \%$ female) reported relevant depressive and $16.3 \%$ reported anxiety symptoms, while $8.4 \%$ experienced both [11]. Students of human and health sciences had the lowest rates of all analyzed study fields, especially regarding depressive symptoms. During the pandemic, hints were found that students' mental health appears to be somewhat poorer. In a sample of students from different German universities ( $N=2,548 ; 74.8 \%$ female; April to May 2020) moderate to severe levels of depression symptoms were found in $35.9 \%$ and moderate to severe anxiety symptoms in $27.7 \%$ of the students [12]. However, this is only a comparison of two cross-sectional surveys, whereas longitudinal data could be more informative. A German longitudinal study of Voltmer et al. [13] reported no significant differences in their student sample regarding general health, stress, as well as depression symptoms; only a minor elevation of anxiety was observed between 2019 and 2020 (June).

A Polish repeated cross-sectional study ( $N=7,228 ; 80.8 \%$ female; [8]) that collected data five times from March to April 2020 could show that psychology students reported significantly lower depression scores compared to other students $(d=0.22)$ and medical students $(d=0.12)$ as well as lower anxiety scores compared to other students $(d=0.07)$. In contrast, students did not differ significantly regarding suicidality and stress. This is an interesting finding, which raises the question of whether German psychology students are less burdened in the pandemic compared to students of other subjects. 
While all these previous studies refer to the period shortly after the onset of the pandemic, the present study analyzes data from students after the third wave during the corona pandemic in Germany. Accordingly, students have now been living with the drastic changes in their university life for almost one and a half years.

\section{Aims and Hypotheses}

This study tries to answer the following central research question: Do German psychology students differ from students of other disciplines in terms of how they were affected by the corona pandemic, their mental health, their alcohol use, and their partnership situation after the third wave?

Due to the unequal distribution of women and men studying psychology in Germany and the different prevalence of mental health problems (e.g., [14]) as well as alcohol consumption (e.g., [15]), the analyses is performed separately for both sexes. Given the lack of available research on this research question, it is not possible to formulate specific hypotheses.

\section{Method}

\section{Study Design}

From July to mid-June 2021, an online survey was conducted as a part of a research project of the Institute of Psychology of the TU Braunschweig. Students from different local universities were asked about their mental health, substance use, partnerships, and sexual behavior. Participants were recruited through social media and the student portals as well as news portals of the universities. Answering the questions took about 15 minutes and among all participants $3 \times 15$ Euro vouchers were raffled. The questionnaire was designed in such a way that no question had to be answered and it was possible to stop the survey at any time. The ethics committee of the TU Braunschweig approved all procedures (BA_2021-14).

\section{Sample Characteristics}

A total of 1057 students had started to fill out the questionnaire, of which 928 (87.8\%) answered the last question. From these 928 students the majority were enrolled at the TU Braunschweig representing the baseline sample for this study $(n=718)$. Since universities sometimes handled containment measures differently, we limit this study to students at the TU Braunschweig to ensure comparability. Furthermore, men and women will be analyzed separately resulting in four sub-samples, whereas individuals who did not assign their gender to either group were excluded $(n=12)$ from this study (final sample $n=706$ ).

The aim of this study is to compare psychology students $(n=127 ; 18.0 \%)$ with students of other subjects from the TU Braunschweig ( $n=579 ; 82.0 \%$ ). The sociodemographic characteristics for these sub-samples are displayed in Table 1. 
Significant differences between the subsamples of female or male students were found in such a way that female psychology students were less likely to live with their partner ( $\mathrm{Chi}^{2}=4.39, p=.036$ ), more likely to pursue a bachelor's degree $\left(\mathrm{Chi}^{2}=16.68, p<.001\right)$, and they were on average enrolled around one semester less $(t=-2.10, p=.037)$ compared to other female students. Male psychology students were an average of around one and half years younger $(Z=-2.15, p=.032)$ as well as three semesters less enrolled $(Z=-2.60, p=.009)$ compared to other male students.

\section{Measures}

The survey consisted of a combination of items to be rated on rating scales and standardized questionnaires.

Rating Scales. Impairment due to corona ([1] no impairment to [6] very strong impairment) and the resulting strain ([1] no stress to [6] very high stress), as well as study stress ([1] not burdened to [6] heavily burdened), concerns about the professional future ([1] no concerns to [6] very strong concerns), the general health status ([1] very bad to [6] very good), and the happiness with the relationship ([0] very unsatisfied to [5] very satisfied) were assessed on six-point scales. A five-point scale was used to rate life satisfaction ([1] very unsatisfied to [5] very satisfied). Finally, loneliness ([0] not at all to [3] almost every day) and happiness with the frequency of sex in

Table 1

Sample Characteristics of the Total Sample and The Four Sub-Samples.

\begin{tabular}{|c|c|c|c|c|c|c|c|}
\hline & Total sample & $\begin{array}{c}\text { Female } \\
\text { psychology } \\
\text { students }\end{array}$ & $\begin{array}{l}\text { Other female } \\
\text { students }\end{array}$ & $\begin{array}{c}\text { Statistics } \\
\text { females } \\
\left(t-/ \text { Chi }^{2} \text {-tests }\right)\end{array}$ & $\begin{array}{c}\text { Male psychology } \\
\text { students }\end{array}$ & $\begin{array}{l}\text { Other male } \\
\text { students }\end{array}$ & $\begin{array}{c}\text { Statistics } \\
\text { males } \\
\text { (U-/Chi'-tests) }\end{array}$ \\
\hline$n$ & 706 & 108 & 322 & & 19 & 257 & \\
\hline Age in years & $23.43(S D=3.86)$ & $23.01(S D=5.00)$ & $22.90(S D=2.91)$ & $t=0.29, p=.776$ & $22.63(S D=3.06)$ & $24.32(S D=4.23)$ & $Z=-2.15, p=.032$ \\
\hline Semesters enrolled & $6.86(S D=4.22)$ & $5.75(S D=3.40)$ & $6.57(S D=3.80)$ & $t=-2.10, p=.037$ & $4.89(S D=3.25)$ & $7.85(S D=4.86)$ & $Z=-2.60, p=.009$ \\
\hline \multicolumn{8}{|l|}{ Living form } \\
\hline Living in shared flats & $34.3 \%$ & $35.2 \%$ & $30.7 \%$ & $\mathrm{Chi}^{2}=6.60, p=.158$ & $42.1 \%$ & $37.9 \%$ & \\
\hline Living alone & $22.8 \%$ & $22.2 \%$ & $19.9 \%$ & (with partner vs. & $26.3 \%$ & $26.6 \%$ & \\
\hline Living with partner & $22.0 \%$ & $19.4 \%$ & $29.8 \%$ & rest: $\mathrm{Chi}^{2}=4.39$, & $5.3 \%$ & $14.5 \%$ & $\mathrm{Chi}^{2}=1.74$ \\
\hline Living with parents & $19.3 \%$ & $19.4 \%$ & $18.3 \%$ & $p=.036)$ & $26.3 \%$ & $19.9 \%$ & $p=.783$ \\
\hline Living with own family & $1.6 \%$ & $3.8 \%$ & $1.3 \%$ & & $0.0 \%$ & $1.1 \%$ & \\
\hline \multicolumn{8}{|l|}{ Next Degree } \\
\hline Bachelor & $61.8 \%$ & $79.6 \%$ & $59.5 \%$ & & $78.9 \%$ & $56.0 \%$ & \\
\hline Master & $29.9 \%$ & $17.6 \%$ & $26.8 \%$ & $\mathrm{Chi}^{2}=16 . \underline{.68, \underline{p}}<.001$ & $21.1 \%$ & $39.7 \%$ & $\mathrm{Chi}^{2}=4.03$ \\
\hline Others (e.g., State Exam) & $8.3 \%$ & $2.8 \%$ & $13.7 \%$ & & $0.0 \%$ & $4.3 \%$ & $p=.134$ \\
\hline
\end{tabular}

partnerships ([0] not at all to [3] very) were assessed using four-point scales. Students were also asked if they were currently receiving psychological and/or psychiatric treatment (yes/no). 
Alcohol Consumption. Students were asked about the number of consumption days in the past 30 days and the type of alcohol consumed (e.g., beer or wine). Based on this information, the pure alcohol consumed (in grams) per day in the last month was calculated. Three groups were formed, based on the criteria of the World Health Organization [16]: Abstainers (0g), low risk (males: $1 \mathrm{~g}$ to $40 \mathrm{~g}$; females: 1g$20 \mathrm{~g}$ ) and medium to very high risk (males: $>40 \mathrm{~g}$; females: $>20 \mathrm{~g}$ ). In addition, the number of days on which binge drinking (males at least five and females at least four drinks) was practiced in the last 30 days was assessed.

Mood Problems (Depressive Symptoms). For the measurement of mood problems in terms of depressive symptoms, the German version of the Patient Health Questionnaire-9 (PHQ-9; [17]) was used. The questionnaire consists of nine items (e.g.,"Over the last two weeks, how often have you been bothered by feeling tired or having little energy?") assessing depressive symptoms according to the DSM-IV criteria and their severity. The rating is made on a four-point scale (not at all [0] to almost every day [3]). The individual items are combined to a total score, whereby higher values indicate more mood problems. The questionnaire shows a good internal consistency of $a=.86$ in our total sample.

Worrying (Anxiety Symptoms). Worrying was assessed with the German version of the Generalized Anxiety Disorder Scale-7 (GAD-7; [18]). The seven items (e.g.,"Over the last two weeks, how often have you been bothered by trouble relaxing?") of the questionnaire measure symptoms of generalized anxiety disorders during the last two weeks and their severity. The rating is made on a four-point scale (not at all [0] to almost every day [3]). The individual items are combined to a total score, whereby higher scores indicate more unspecific worrying. The questionnaire has a high internal consistency of $a=.87$ in our total sample.

\section{Statistical Analyses}

To analyze the data from women, t-tests and $\mathrm{Chi}^{2}$-tests were calculated to detect significant differences. The sample of men studying psychology is very small $(n=19)$, therefore Mann-Whitney U-tests and Chi²tests were calculated. The results for this sub-sample are exploratory and should be interpreted with caution.

Since multiple testing is involved in this study, the alpha error is corrected with the help of the Bonferroni correction. Differences in eighteen characteristics are tested for women and men separately. To find a compromise between the reduction of the alpha error and the simultaneous increase of the beta error, an alpha of $.05 / 18=.00278$ is assumed. Effect sizes are calculated additionally. We follow the usual conventions of Cohen [19] for interpretation: $d>0.20$ small, $d>0.50$ medium, $d>0.80$ strong effect; Cramer's $V>0.10$ small, $V>0.30$ medium, $V>0.50$ strong effect.

\section{Results}

\section{Comparison of Female Psychology Students and Other Female Students}


Regarding mental health (Table 2), female psychology students $(M=8.40, S D=5.20)$ reported significant $(t=-6.13, p<.001, d=0.68)$ lower mean values on the PHQ-9 for mood problems compared to other female students $(M=12.07, S D=5.45)$. Furthermore, they were also significantly more often in the category of non-minimal or mild symptoms $\left(\mathrm{Chi}^{2}=45.09, p<.001\right.$, Cramer's $\mathrm{V}=.32$ ).

A similar pattern was found for worrying. Female psychology students $(M=6.12, S D=4.28)$ reported significant $(t=-5.59, p<.001, d=0.62)$ lower mean values on the GAD-7 compared to other female students $(M=9.00, S D=4.75)$ as well. Female psychology students were significantly more often $\left(\mathrm{Chi}^{2}=31.37, p<.001\right.$, Cramer's V $\left.=.27\right)$ in the non-minimal category, while other students were more frequently in the severe category (14.9\%). Only $1 \%$ of female psychology students were in the latter category.

Table 2

Descriptive Data and Comparison of the State of Mental Health of Psychology Students and Students of Other Subjects. 


\begin{tabular}{|c|c|c|c|c|}
\hline & $\begin{array}{l}\text { Female psychology } \\
\text { students }\end{array}$ & $\begin{array}{l}\text { Other female } \\
\text { students }\end{array}$ & $\begin{array}{l}\text { Male psychology } \\
\text { students }\end{array}$ & $\begin{array}{l}\text { Other male } \\
\text { students }\end{array}$ \\
\hline$n$ & 108 & 322 & 19 & 257 \\
\hline \multicolumn{5}{|c|}{ PHQ-9 (mood problems) } \\
\hline$M(S D)$ & $8.40(5.20)$ & $12.07(5.45)$ & $8.11(6.33)$ & $10.03(5.65)$ \\
\hline$t$-test & \multicolumn{2}{|c|}{$t=-6.13, p<.001, d=0.68$} & \multicolumn{2}{|c|}{$Z=-1.81, p=.071, d=0.22$} \\
\hline \multicolumn{5}{|c|}{ Frequencies of the categories } \\
\hline $\begin{array}{l}\text { None-minimal } \\
(0-4)\end{array}$ & $22.2 \%$ & $7.5 \%$ & $31.6 \%$ & $17.9 \%$ \\
\hline $\begin{array}{l}\text { Mild } \\
(5-9)\end{array}$ & $46.3 \%$ & $26.4 \%$ & $42.1 \%$ & $31.9 \%$ \\
\hline $\begin{array}{l}\text { Moderate } \\
(10-14)\end{array}$ & $13.9 \%$ & $32.9 \%$ & $10.5 \%$ & $26.8 \%$ \\
\hline $\begin{array}{l}\text { Moderately severe } \\
(15-19)\end{array}$ & $15.7 \%$ & $23.6 \%$ & $5.3 \%$ & $17.9 \%$ \\
\hline $\begin{array}{l}\text { Severe } \\
(20-27)\end{array}$ & $1.9 \%$ & $9.6 \%$ & $10.5 \%$ & $5.4 \%$ \\
\hline Chi²-test & \multicolumn{2}{|c|}{$\mathrm{Chi}^{2}=45.09, p<.001$, Cramer's V $=.32$} & \multicolumn{2}{|c|}{$\mathrm{Chi}^{2}=6.60, p=.159$, Cramer's V $=.16$} \\
\hline \multicolumn{5}{|l|}{ GAD-7 (worrying) } \\
\hline$M(S D)$ & $6.12(4.28)$ & $9.00(4.75)$ & $5.32(3.97)$ & $7.03(4.64)$ \\
\hline$t$-test & \multicolumn{2}{|c|}{$t=-5.59, p<.001, d=0.62$} & \multicolumn{2}{|c|}{$Z=-1.65, p=.099, d=0.20$} \\
\hline \multicolumn{5}{|c|}{ Frequencies of the categories } \\
\hline $\begin{array}{l}\text { None-minimal } \\
(0-4)\end{array}$ & $38.9 \%$ & $17.4 \%$ & $42.1 \%$ & $34.6 \%$ \\
\hline $\begin{array}{l}\text { Mild } \\
(5-9)\end{array}$ & $38.9 \%$ & $40.7 \%$ & $42.1 \%$ & $38.9 \%$ \\
\hline $\begin{array}{l}\text { Moderate } \\
(10-14)\end{array}$ & $21.3 \%$ & $27.0 \%$ & $15.8 \%$ & $19.1 \%$ \\
\hline
\end{tabular}

Note. The alpha error is corrected with the help of the Bonferroni correction: $a=.05 / 18=.00278$. 


\begin{tabular}{|c|c|c|c|c|}
\hline & $\begin{array}{l}\text { Female psychology } \\
\text { students }\end{array}$ & $\begin{array}{l}\text { Other female } \\
\text { students }\end{array}$ & $\begin{array}{l}\text { Male psychology } \\
\text { students }\end{array}$ & $\begin{array}{l}\text { Other male } \\
\text { students }\end{array}$ \\
\hline $\begin{array}{l}\text { Severe } \\
(15-21)\end{array}$ & $0.9 \%$ & $14.9 \%$ & $0.0 \%$ & $7.4 \%$ \\
\hline Chi²-test & \multicolumn{2}{|c|}{$\mathrm{Chi}^{2}=31.37, p<.001$, Cramer's V $=.27$} & \multicolumn{2}{|c|}{ Chi $^{2}=1.83, p=.608$, Cramer's V $=.08$} \\
\hline \multirow{2}{*}{$\begin{array}{l}\text { PHQ-9 and GAD-7 } \\
\geq 10\end{array}$} & $19.4 \%$ & $39.8 \%$ & $15.8 \%$ & $24.9 \%$ \\
\hline & \multicolumn{2}{|c|}{ Chi $^{2}=14.73, p<.001$, Cramer's V $=.19$} & \multicolumn{2}{|c|}{$\mathrm{Chi}^{2}=0.80, p=.371$, Cramer's V $=.05$} \\
\hline
\end{tabular}

\section{Table 3}

Descriptive Data and Comparison of Different Characteristics of Female Psychology Students $(n=108)$ and Female Students of Other Subjects $(n=322)$. 


\section{Female psychology students \\ Other female \\ students \\ $M(S D)$ \\ $M(S D)$}

Stress during corona

\begin{tabular}{llll} 
Impairment due to corona & $4.18(1.21)$ & $4.47(1.14)$ & $t=-2.28, p=.023, d=0.25$ \\
\hline Strain due to impairment & $3.81(1.21)$ & $4.16(1.15)$ & $t=-2.67, p=.008, d=0.30$ \\
\hline $\begin{array}{l}\text { Study stress } \\
\text { Concerns about } \\
\text { professional future }\end{array}$ & $2.00(1.03)$ & $4.27(1.11)$ & $t=-2.34, p=.020, d=0.25$ \\
\hline
\end{tabular}

General health

General health status

$4.20(1.01)$

3.66 (1.10)

$t=4.52, p<.001, d=-0.50$

Loneliness

$1.96(0.84)$

$2.23(0.98)$

$t=-2.74, p=.007, d=0.29$

Life satisfaction

$3.50(0.86)$

$3.06(0.96)$

$t=4.20, p<.001, d=-0.47$

Psychological/psychiatric $\quad 14.0 \%$

$12.1 \%$

$\mathrm{Chi}^{2}=0.27, p=.606$, treatment

Alcohol consumption

FMI (in g)

9.16 (19.91)

9.06 (16.87)

$t=0.05, p=.960, d=-0.01$

Binge Drinking (30 days)

1.44 (2.63)

2.30 (3.94)

$t=-2.54, p=.012, d=0.24$

Categories alcohol $26.9 \%$

$26.9 \%$

$\mathrm{Chi}^{2}=1.56, p=.458$,

Abstinent

$63.9 \%$

$59.4 \%$

Cramer's V $=.06$

Low risk

$9.3 \%$

$13.8 \%$

Medium - very high risk

\section{Partnership}

$\begin{array}{llll}\begin{array}{l}\text { Satisfaction with } \\ \text { partnership }\end{array} & n=71 & n=217 & t=1.07, p=.287, d=-0.15 \\ & 3.97(0.93) & 3.81(1.15) & \\ \begin{array}{l}\text { Satisfaction with sex in } \\ \text { partnership }\end{array} & n=71 & n=214 & t=0.68, p=.501, d=-0.09 \\ & 3.06(0.79) & 2.98(0.89) & \end{array}$

Note. The alpha error is corrected with the help of the Bonferroni correction: $a=.05 / 18=.00278$.

Simultaneous clinically relevant anxiety and depression symptoms (both $\geq 10$ ) were reported by $19.4 \%$ of the female psychology students and by $39.8 \%$ of other female students $\left(\mathrm{Chi}^{2}=14.73, p<.001\right.$, Cramer's V 
$=.19)$.

Female psychology students rated their general health $(t=4.52, p<.001, d=-0.50)$ and life satisfaction ( $t=$ $4.20, p<.001, d=-0.47$ ) significantly higher compared to other female students (Table 3 ).

Small effect sizes were found in such a way that psychology students reported less impairment ( $t=-2.28$, $p=.023, d=0.25)$ and strain due to the impairment $(t=-2.67, p=.008, d=0.30)$ during corona, less study stress $(t=-2.34, p=.020, d=0.25)$, and loneliness $(t=-2.74, p=.007, d=0.29)$ as well as less days with binge drinking $(t=-2.54, p=.012, d=0.24)$. These effects were significant at the alpha level of .05 ; however, after the Bonferroni correction, they could not reach the new alpha level of .00278, as did the results presented previously. No significant effects were found for the concerns about the professional future, psychological/psychiatric treatment, pure alcohol consumption, satisfaction with the partnership and the frequency of sex in partnerships.

\section{Comparison of Male Psychology Students and Other Male Students}

Male psychology students $(M=8.11, S D=6.33)$ also had tendential slightly lower mean scores regarding mood problems compared to other male students $(M=10.03, S D=5.65)$, but this difference was not significant (Table 2). The mean scores on the GAD-7 were also tendential slightly lower on the GAD-7 for male psychology students $(M=5.32, S D=3.97)$ compared to students of other subjects $(M=7.03, S D=$ 4.64 ), but this difference was not significant as well. Additionally, no significant differences were found in the distributions of the categories. Simultaneous relevant anxiety and depression symptoms (both $\geq 10)$ were reported by $15.8 \%$ of the male psychology students and by $24.9 \%$ of the other male students.

Table 4

Descriptive Data and Comparison of Different Characteristics of Male Psychology Students $(n=19)$ and Male Students of Other Subjects $(n=257)$. 


\begin{tabular}{|c|c|c|c|}
\hline & $\begin{array}{l}\text { Male psychology } \\
\text { students }\end{array}$ & $\begin{array}{l}\text { Male students of } \\
\text { other subjects }\end{array}$ & Statistics \\
\hline & $M(S D)$ & $M(S D)$ & \\
\hline \multicolumn{4}{|l|}{ Stress during Corona } \\
\hline Impairment due to corona & $4.16(1.02)$ & $4.37(1.28)$ & $\begin{array}{l}Z=-1.05, p=.294, d= \\
0.12\end{array}$ \\
\hline Strain due to impairment & $3.21(1.08)$ & $3.89(1.25)$ & $\begin{array}{l}Z=-2.48, p=.013, d= \\
0.29\end{array}$ \\
\hline Study stress & $3.58(1.02)$ & $4.16(1.05)$ & $\begin{array}{l}Z=-2.34, p=.020, d= \\
0.27\end{array}$ \\
\hline $\begin{array}{l}\text { Concerns about } \\
\text { professional future }\end{array}$ & $1.84(1.07)$ & $2.88(1.57)$ & $\begin{array}{l}Z=-2.94, p=.003, d= \\
0.35\end{array}$ \\
\hline \multicolumn{4}{|l|}{ General health } \\
\hline General health status & $4.32(1.10)$ & $3.90(1.21)$ & $\begin{array}{l}Z=-1.49, p=.135, d= \\
0.18\end{array}$ \\
\hline Loneliness & $1.89(0.94)$ & $2.24(1.01)$ & $\begin{array}{l}Z=-1.50, p=.135, d= \\
0.17\end{array}$ \\
\hline Life satisfaction & $3.53(1.07)$ & $3.18(0.99)$ & $\begin{array}{l}Z=-1.57, p=.116, d= \\
0.18\end{array}$ \\
\hline $\begin{array}{l}\text { Psychological/psychiatric } \\
\text { treatment }\end{array}$ & $5.3 \%$ & $8.9 \%$ & $\begin{array}{l}\mathrm{Chi}^{2}=0.30, p=.582 \\
\text { Cramer's V }=.03\end{array}$ \\
\hline \multicolumn{4}{|l|}{ Alcohol consumption } \\
\hline FMI (in g) & $7.82(13.27)$ & $20.93(37.67)$ & $Z=-1.73 p=.083, d=0.21$ \\
\hline Binge Drinking (30 days) & $1.74(2.62)$ & $3.38(4.60)$ & $\begin{array}{l}Z=-1.43, p=.154, d= \\
0.17\end{array}$ \\
\hline Categories alcohol & $26.3 \%$ & $21.8 \%$ & \multirow[t]{4}{*}{$\begin{array}{l}\mathrm{Chi}^{2}=1.37, p=.504 \\
\text { Cramer's V = .07 }\end{array}$} \\
\hline Abstinent & $68.4 \%$ & $63.4 \%$ & \\
\hline Low risk & $5.3 \%$ & $14.8 \%$ & \\
\hline Medium - very high risk & & & \\
\hline \multicolumn{4}{|l|}{ Partnerships } \\
\hline \multirow{2}{*}{$\begin{array}{l}\text { Satisfaction with } \\
\text { partnership }\end{array}$} & $n=8$ & $n=122$ & \multirow{2}{*}{$\begin{array}{l}Z=-1.23, p=.218, d= \\
0.20\end{array}$} \\
\hline & $3.00(1.51)$ & $3.70(0.89)$ & \\
\hline
\end{tabular}

Note. The alpha error is corrected with the help of the Bonferroni correction: $a=.05 / 18=.00278$. 


\begin{tabular}{|llll|}
\hline & $\begin{array}{l}\text { Male psychology } \\
\text { students } \\
M(S D)\end{array}$ & $\begin{array}{l}\text { Male students of } \\
\text { other subjects } \\
M(S D)\end{array}$ & Statistics \\
\hline $\begin{array}{l}\text { Satisfaction with sex in } \\
\text { partnership }\end{array}$ & $n=8$ & $n=122$ & $Z=-0.66, p=.509, d=$ \\
& $2.63(0.92)$ & $2.84(0.89)$ & 0.11 \\
\hline Note. The alpha error is corrected with the help of the Bonferroni correction: $\mathrm{a}=.05 / 18=.00278$. \\
\hline
\end{tabular}

Male psychology students reported significant less $(Z=-2.94, p=.003, d=0.35)$ concerns about their professional future (Table 4 ). Small effect sizes were found in such a way that male psychology students showed lower strain due to the impairment during corona $(Z=-2.48, p=.013, d=0.29)$ and less study stress $(Z=-2.34, p=.020, d=0.27)$ compared to other male students. These effects were significant at the alpha level of .05; however, after the Bonferroni correction, they could not reach the new alpha level of .00278. No significant differences were found for the individual aspects of general health, alcohol consumption and partnerships.

\section{Discussion}

This study analyzed whether there are differences between psychology students and students of other subjects regarding mental health, alcohol consumption, and partnerships after the third wave during the corona pandemic. In the section following, we compare our results with the data from other studies before and at the beginning of the pandemic. However, many of the studies did not report the results separately by gender, therefore a differentiated comparison is only possible to a limited extent. The aim of the presentation is to enable a better assessment of the results, since other comparable studies are still missing in Germany.

Female psychology students (PHQ-9:M=8.40; GAD-7:M=6.12) showed significantly fewer symptoms in terms of mood problems and worrying compared to other female students (PHQ-9:M=12.07; GAD7:M=9.00) in our sample. In Germany, pre-pandemic mean values of 6.77 for the PHQ-9 and 6.23 for the GAD-7 were reported in 2016 [20], while the reported mean values after the first wave during the pandemic for the PHQ-9 (female: $M=8.19$; male: $M=8.78$; [10]) and GAD-7 $(M=7.14$; [12]) were higher. Female psychology students appear to be closer to these values compared to other female students reporting higher values on average for depressive mood problems and worrying.

For male psychology students (PHQ-9: $M=8.11 ; G A D-7: M=5.32$ ), there are similar trends in the comparison with other male students (PHQ-9:M=10.03; GAD-7:M=7.03), although the differences were not significant probably due to the small sample size and the resulting low power.

Significantly fewer psychology students were above the cut-off for clinically relevant mood problems (31.5\%), worrying (22.2\%) and both simultaneously (19.4\%) compared to other female students (PHQ-9: 
66.1\%; GAD-7: $41.9 \%$; both: $39.8 \%$ ). Before the pandemic Wörfel et al. [11] reported that $14.2 \%$ of the German students showed clinically relevant depressive and $16.3 \%$ anxiety symptoms, while $8.4 \%$ experienced both. Karing [12] found in her study after the first wave that $35.9 \%$ of the students showed relevant depressive and $27.7 \%$ relevant anxiety symptoms. Again, psychology students are more likely to be at the previously reported levels, while other students are significantly above these values.

A similar picture emerges among male students, whereas fewer male psychology students reported clinically relevant mood problems $(26.3 \%)$, worrying $(15.8 \%)$ and both simultaneously (15.8\%) compared to other male students (PHQ-9: 50.1\%; GAD-7: 26.5\%; both: $24.9 \%$ ).

Furthermore, female psychology students rated their overall health and life satisfaction significantly higher, while they also tended to be less stressed by the pandemic and their studies, feel less lonely, and report fewer days of binge drinking. Male psychology students had significantly fewer concerns about their professional future compared to other male students. Tendentially, they also reported less impairment due to corona and study stress. Significant differences with regard to partnerships were not found for either male or female psychology students. For a more detailed analysis of German students' partnerships and sexuality after the third wave of the pandemic, see Supke et al. [21].

It should be noted that around $15 \%$ of the students in our sample received psychological and/or psychiatric treatment at the time of the survey. This is slightly more than what would be expected. For example, Kohls et al. [10] reported that $8 \%$ of the investigated students in their study were currently under treatment. One explanation for this could be that some students have decided to seek help during the pandemic because of greater perceived stress. Furthermore, we did not distinguish between offers by professionals or universities (e.g., counseling centers). Interestingly, there were no significant differences between the students, although psychology students could be more willing to seek psychological help.

In summary, we found hints that psychology students, especially female students, appear to be less psychologically distressed in terms of depressive mood problems and worrying during the pandemic. A possible explanation for our findings is provided by the results of a Chinese study of Cheng et al. [22]. They found hints in their pre-pandemic data that higher mental health knowledge was associated with lower levels of depressive symptoms. Psychology students learn a lot about mental disorders and how to promote mental well-being within their studies. In a crisis, this could be helpful in coping with higher perceived stress and drastic changes in their daily life.

\section{Limitations}

In our study, some limitations should be considered. First, the sample of male psychology students is small, which may explain why there were no significant effects found regarding differences in mental health. At the TU Braunschweig (women: 84.3\%), as well as in Germany, significantly more women than men study psychology which is also reflected in our sample (women: 85.0\%). However, the ratio in the 
students of the TU Braunschweig is different (women: 41.1\%). Furthermore, there were significant differences in the comparison of the sub-samples, which also limits the generalizability. Second, there is very little comparable gender-specific data for the PHQ-9 and GAD-7 for the student population. Third, the individual faculties and fields of study were not differentially analyzed.

\section{Conclusion}

Overall, it can be concluded that the mental health of psychology students, especially female students, seems to be better compared to students of other subjects. Future research could search for the reasons for these differences. Furthermore, longitudinal studies are desirable, as they could reveal whether psychology students are more resilient to the changes during the pandemic or if they show fewer mental health symptoms overall and experience the same increase within the pandemic as other students. Perhaps the results obtained could be used to provide insights into how to more effectively support students in need of assistance during a crisis such as a pandemic.

There are now several findings on the psychosocial impact of the corona pandemic on students. An unanswered question is how university employees deal with the pandemic and the resulting psychosocial consequences.

\section{Declarations}

Ethics Approval and Consent to Participate. The research project received ethical approval by the ethics committee of the Technische Universität Braunschweig (BA_2021-14). All methods were performed in accordance with the Declaration of Helsinki and the relevant BioMed Central guidelines and regulations. Participation in the questionnaire was voluntary and informed consent was given by all of the students before the start of the survey.

Consent for Publication. Not applicable.

Availability of Data and Materials. The data being analyzed during the current study can be requested from Max Supke (m.supke@tu-braunschweig.de) and are available for further research on reasonable requests. The questionnaires used can be found in the corresponding references.

Competing Interests. The authors have no relevant financial or non-financial interests to disclose.

Funding. The Open Access Publication of Technische Universität Braunschweig supports us with funds for the open access publication of this manuscript within the framework of Project Deal.

Authors' Contributions. MS wrote $60 \%$ of the manuscript and performed $60 \%$ of the data analysis and WS $40 \%$ manuscript/analysis. All authors have read and approved the final manuscript and ensure that this is the case. 
Acknowledgements. We thank the students for their participation in our study and the positive feedback on our research project.

\section{References}

[1] Rajkumar RP. COVID-19 and mental health: A review of the existing literature. Asian Journal of Psychiatry. 2020;52:Article 102066. https://doi.org/10.1016/j.ajp.2020.102066

[2] Shultz JM, Cooper JL, Baingana F, Oquendo MA, Espinel Z, Althouse BM et al. The role of fear-related behaviors in the 2013-2016 West Africa Ebola virus disease outbreak. Current Psychiatry Reports. 2016;18:Article 104. https://doi.org/10.1007/s11920-016-0741-y

[3] Gaertner B, Fuchs J, Möhler R, Meyer G, Scheidt-Nave C. Older people at the beginning of the COVID-19 pandemic: A scoping review. Journal of Health Monitoring. 2021; 6(S4):1-34.

https://doi.org/10.25646/7857

[4] Hahlweg K, Ditzen B, Job A-K, Gastner J, Schulz W, Supke M, Walper S. COVID-19: Psychologische Folgen für Familie, Kinder und Partnerschaft [COVID-19: Psychological Consequences for Family Life, Children, and Partnership]. Zeitschrift für Klinische Psychologie und Psychotherapie. 2021;49:157-71. https://doi.org/10.1026/1616-3443/a000592

[5] Aristovnik A, Keržič D, Ravšelj D, Tomaževič N, Umek L. Impacts of the COVID-19 pandemic on life of higher education students: A global perspective. Sustainability. 2020;12(20):Article 8438. https://doi.org/10.3390/su12208438

[6] Elmer T, Mepham K, Stadtfeld C. Students under lockdown: Comparisons of students' social networks and mental health before and during the COVID-19 crisis in Switzerland. PLoS ONE. 2020;15(7):Article e0236337. https://doi.org/10.1371/journal.pone.0236337

[7] Bourion-Bédès S, Tarquinio C, Batt M, Tarquinio P, Lebreuilly R, Sorsana C et al. Stress and associated factors among French university students under the COVID-19 lockdown: The results of the PIMS-CoV 19 study. Journal of Affective Disorders. 2021;283:108-14. https://doi.org/10.1016/j.jad.2021.01.041

[8] Debowska A, Horeczy B, Boduszek D, Dolinski D. A repeated cross-sectional survey assessing university students' stress, depression, anxiety, and suicidality in the early stages of the COVID-19 pandemic in Poland. Psychological Medicine. 2020;1-4. https://doi.org/10.1017/S003329172000392X

[9] Busse H, Buck C, Stock C, Zeeb H, Pischke CR, Fialho P et al. Engagement in health risk behaviours before and during the COVID-19 pandemic in German university students: Results of a cross-sectional study. International Journal of Environmental Research and Public Health. 2021;18(4):Article 1410. https://doi.org/10.3390/ijerph18041410 
[10] Kohls E, Baldofski S, Moeller R, Klemm S-L, Rummel-Kluge C. Mental health, social and emotional well-being, and perceived burdens of university students during COVID-19 pandemic lockdown in Germany. Frontiers in Psychiatry. 2021;12:Article 643957. https://doi.org/10.3389/fpsyt.2021.643957

[11] Wörfel F, Gusy B, Lohmann K, Töpritz K, Kleiber D. Mental health problems among university students and the impact of structural conditions. Journal of Public Health. 2016;24:125-33.

https://doi.org/10.1007/s10389-015-0703-6

[12] Karing C. Prevalence and predictors of anxiety, depression and stress among university students during the period of the first lockdown in Germany. Journal of Affective Disorders Reports. 2021;5:Article 100174. https://doi.org/10.1016/j.jadr.2021.100174

[13] Voltmer E, Köslich-Strumann S, Walther A, Kasem M, Obst K, Kötter T. The impact of the COVID-19 pandemic on stress, mental health and coping behavior in German University students - A longitudinal study before and after the onset of the pandemic. BMC Public Health. 2021;21:Article 1385. https://doi.org/10.1186/s12889-021-11295-6

[14] Otten D, Tibubos AN, Schomerus G, Brähler E, Binder H, Kruse J et al. Similarities and differences of mental health in women and men: A systematic review of findings in three large German cohorts. Frontiers in Public Health. 2021; 9:Article 553071. https://doi.org/10.3389/fpubh.2021.553071

[15] Orth B, Merkel C. Die Drogenaffinität Jugendlicher in der Bundesrepublik Deutschland 2019. Rauchen, Alkoholkonsum und Konsum illegaler Drogen: Aktuelle Verbreitung und Trends. BZgA-Forschungsbericht [Drug affinity among young people in Germany 2019. Smoking, alcohol consumption and use of illicit drugs: Current prevalence and trends. BZgA Research Report]. Köln: Bundeszentrale für gesundheitliche Aufklärung; 2020. https://doi.org/10.17623/BZGA:225-DAS19-DE-1.0

[16] WHO. International guide for monitoring alcohol consumption and related harm. World Health Organization; 2000.

[17] Kroenke K, Spitzer RL, Williams JBW. The PHQ-9: Validity of a brief depression severity measure. Journal of General Internal Medicine. 2001;16:606-13. https://doi.org/10.1046/j.1525-

1497.2001.016009606.x

[18] Spitzer RL, Kroenke K, Williams JBW, Löwe B. A brief measure for assessing generalized anxiety disorder: The GAD-7. JAMA Archives of Internal Medicine. 2006;166:1092-97.

https://doi.org/10.1001/archinte.166.10.1092

[19] Cohen J. Statistical power analysis for the behavioral sciences (2nd ed.). New York: Routledge; 1988. https://doi.org/10.4324/9780203771587

[20] Zhou Y, Xu J, Rief W. Are comparisons of mental disorders between Chinese and German students possible? An examination of measurement invariance for the PHQ-15, PHQ-9 and GAD-7. BMC Psychiatry. 
[21] Supke M, Hahlweg K, Kelani K, Muschalla B, Schulz W. Mental Health, partnerships, and sexual behavior of German students after the third wave during the corona pandemic. 25 August 2021, PREPRINT (Version 1) available at Research Square https://doi.org/10.21203/rs.3.rs-842233/v1

[22] Cheng S, An D, Yao Z, Liu JJ-W, Ning X, Wong JP-H et al. Association between mental health knowledge level and depressive symptoms among Chinese college students. International Journal of Environmental Research and Public Health. 2021;18(4): Article 1850.

https://doi.org/10.3390/ijerph18041850 